\title{
Leprosy Survey of Gutu Province, Southern Rhodesia
}

\author{
BERNARD MOISER. \\ PART I. \\ Fuly 18th to 26th, 1932.
}

Geography, etc.

Gutu Province is a triangular area lying between $19^{\circ}$ and $20^{\circ}$ South and $31^{\circ}$ and $32^{\circ}$ East.

The altitude is about 4,600 feet at the west end, and falls to about 3,000 feet towards the east end.

The country is undulating, well-wooded and broken up by granite hills and kopjies. It is well watered by several rivers, most of them being tributaries of the Devuli River. (See rough sketch map.)

\section{Climatic.}

Average rainfall is about 30 inches per annum, most of which falls between November and May.

Sharp frosts occur during June, July and August, but the climate is hot during March and October.

Population.

The total native population is estimated at 50,000 . They belong to the Karanga tribe, an offshoot of the Bantu 
family. They are of short stature and poorly developed, polygamous, and live in small collections of mud and timberthatched circular huts, scattered about.

There are no large towns. 'Their religion appears to be the worship of departed spirits. They are very unclean in their habits, and have no kind of sanitation whatever.

\section{Occupation.}

Is almost entirely agricultural, the main crops being maize and millet of various sorts. They own large numbers of cattle and goats. Pigs, sheep and poultry are also kept. They do very little fishing, crocodiles being plentiful in the rivers.

Rough Sketch Map of Gutu Province,

Fort Victoria District, S. Rhodesia.

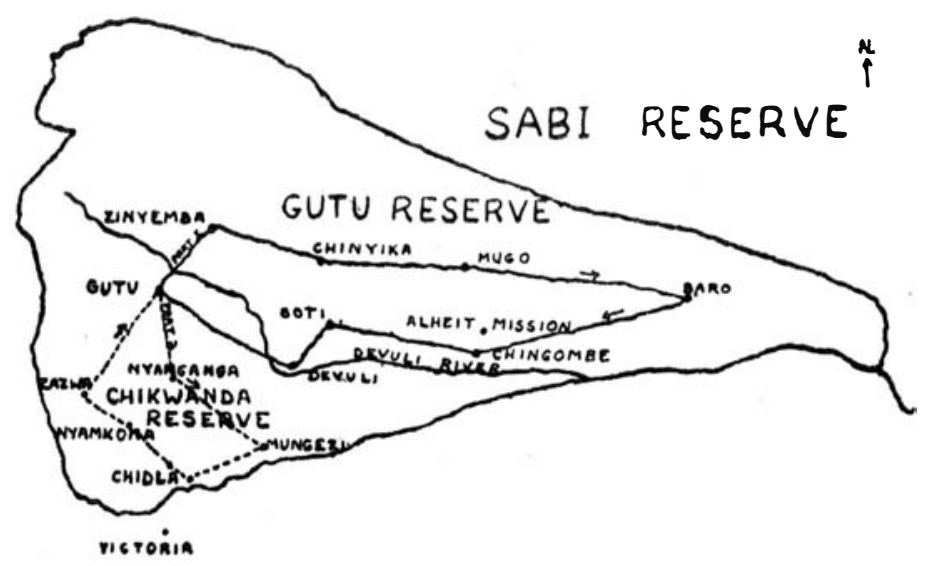

\section{Diseases.-General.}

Eye troubles are exceedingly common, particularly large corneal opacities, hypopyon and even total destruction of the eye. Almost all of them are caused by injury by thorns and sharp pointed grasses in childhood. A few appear to have been caused by smallpox. Conjunctivitis and marginal blepharitis are also all too prevalent and cause much suffering. Phlyctenular conjunctivitis and cataract are not uncommon. Impetigo is also very common, especially amongst children and is sometimes caused by scabies.

Syphilitic manifestations are quite rare, absolutely contrary to the popular belief that the " natives are rotten with syphilis." This was also found to be the case in Chibi Province in 1930, and I am of opinion that it will be found to be true all over Southern Rhodesia, with the exception 
of the vicinity of the large mines (gold, asbestos, etc.). Gonorrhœa and soft chancres were not seen at all, but only males were examined and not all of them. There was no evidence of tuberculosis or malignant disease. Enlarged tonsils are very common.

A curious feature was the large number of people with small multiple umbilicated warts, particularly on the face. There was a good deal of evidence of epidemics of variola, especially in the Eastern Districts. Acne of the face was often seen, as was tinea versicolor of the upper chest and neck.

\section{Leprosy.}

Only six cases of leprosy were discovered, four being males and two females. Four of the cases were seen at Zinyemba, the first examination centre, near Gutu, and I am of opinion that none was aware of the nature of the complaint.

Two of these were man and wife. 'I'he remaining two came from different kraals and each declared that there were no similar patients at their houses. Mugo produced one case, who is now on his way to Ngomahuru for treatment. The last case was seen at a kraal between Devuli and Gutu -an old advanced female case, who also is on her way here.

These six cases are summarised as follows :-

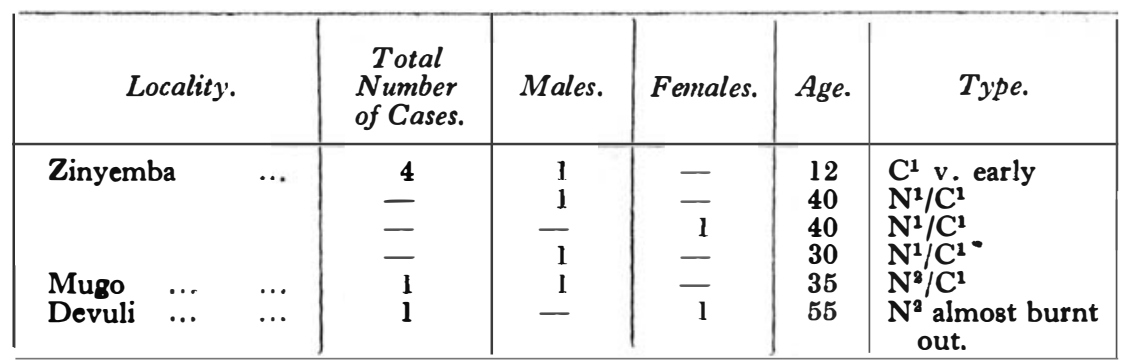

It will be noticed that no advanced cutaneous cases presented themselves; such cases must surely occur and it can only be supposed that they were unwilling to come forward. Six cases amongst 4,855 gives a figure of $1 \cdot 23$ per thousand.

The leprosy case incidence figure of $1 \cdot 23$ per thousand is of little value for the reasons given above, namely, that the proportion of the population examined is very small, about one-sixth, and advanced cases did not appear at all. It must be remembered, however, that nothing of this sort has ever been undertaken in Gutu before. The people are still very much af raid of the Leprosy Suppression Ordinance and it will take time to overcome this. 
The voluntary system of segregation is the one aimed at in Southern Rhodesia.

Details of Itinerary, Etc.

The party consisted of Mr. F. E. Fynn, N.C., of Gutu Province, who very kindly madc the opportunity to accompany us, Dr. Leggate, Mtoko, in charge of the Mtoko Leprosy Hospital, my wife, myself, onc native dresser and certain native messengers.

Gutu is considered a backward area, so disappointments were expected. 'The first was encountered at Gutu itself on the very first day for only some 80 men put in an appearance. Not a woman or child was to be seen.

It took Mr. Fynn some considerable time to discover that a report had been spread that women would be stripped for examination. The contrary had been especially stated, since no European female nurses accompanied us, as was the case during the Chibi survey. I had come to the conclusion during the Chibi survey that nurses were not necessary and were a possible source of error, since we have no nurses specially trained in leprosy work in Southern Rhodesia.

Mr Fynn at once sent out messengers to contradict the rumour, and later it was found that more women and children attended than men, but it became apparent that sick people were not putting in an appearance, and that we were examining only a small proportion of the total population.

Total population 50,000, examined 4,855 only, in an area more than half of the province, as follows :-

\begin{tabular}{|c|c|c|c|c|c|c|}
\hline & Males & $\begin{array}{l}F e- \\
\text { males }\end{array}$ & Children & Total & Leprosy & Syphilis \\
\hline 19-7-32 Zinyemba Dip Tank & 83 & 228 & 218 & 529 & 4 & 4 \\
\hline 20-7-32 Narira School $\ldots$ & - & - & 18 & 18 & 0 & 4 \\
\hline Godzi School & & - & 7.2 & 72 & 0 & 8 \\
\hline $\begin{array}{l}\text { Chinyika Dip Tank } \\
\text { 21-7-32 (cold dull dave }\end{array}$ & 87 & 80 & 110 & 277 & 0 & 0 \\
\hline D.T. ... & 101 & 77 & 77 & 255 & 1 & 2 \\
\hline 22-7-32 Baro Dip Tank $\ldots$ & 183 & 261 & 204 & 648 & 0 & 0 \\
\hline $\begin{array}{c}\text { Schl. } \\
\text { Chingomge }\end{array}$ & 105 & 35 & - & 140 & 0 & 0 \\
\hline Tank . & 72 & 131 & 188 & 391 & 0 & 0 \\
\hline 24-7-32 Soti Dip Tank & 119 & 91 & 71 & 281 & $0 \begin{array}{l}0 \\
\text { of }\end{array}$ & $\begin{array}{l}\text { aneurisn } \\
\text { aorta }\end{array}$ \\
\hline \multirow{3}{*}{$\begin{array}{l}25-7-32 \\
26-7-32\end{array}$} & 272 & 460 & 270 & 1002 & 1 & 4 \\
\hline & 200 & 580 & & 1242 & 0 & \\
\hline & & & 'Total & 4855 & 6 & 30 \\
\hline
\end{tabular}

The weather happened to be very cold, far more severe than usual; with sharp frosts almost every night. Corn- 
thrashing was also in progress everywhere, as well as the national ceremony of beer drinking, but I think that the order to natives to attend might with advantage have been made more unmistakable and stringent.

Southern Rhodesia has an estimated population of only a little more than a million. Wage earning males are all registered for taxation and other purposes. The people are well under control and it would seem an easy matter to register every obvious case of leprosy. Whether or not such cases could be persuaded to come to the hospitals for treatment is a different matter. But this is only a question of time. It will pay to go slowly and it is hoped that the second part of this survey of Gutu will produce much better results.

\section{PART II.}

August 1st to 6th, 1932 .

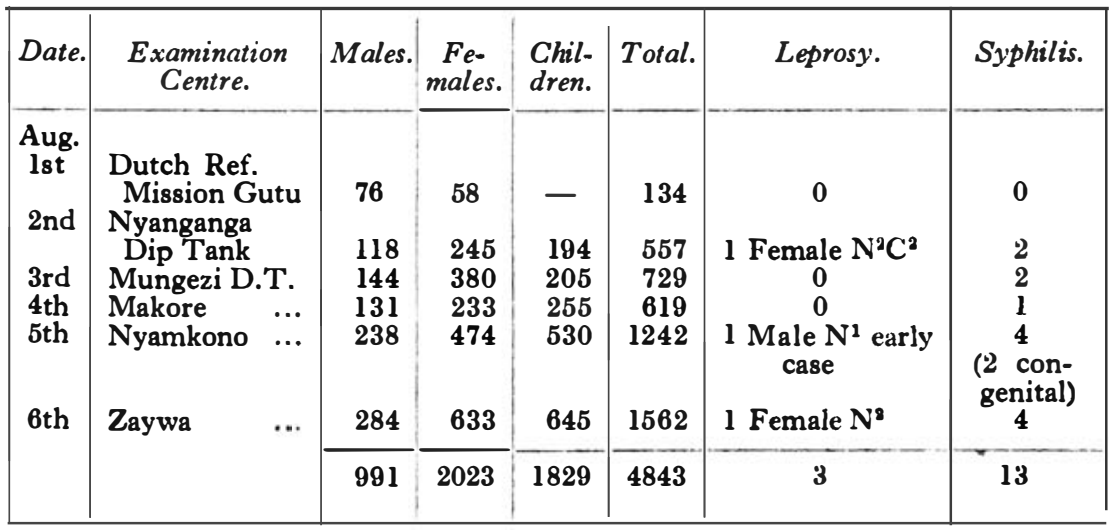

\section{Diseases.-General.}

The remarks under this heading in the report of Part I apply equally to Part II.

It was discovered that the "Multiple umbilicated warts " were merely small sebaceous cysts.

Leprosy.

Only three cases were found, one male and two females. The male was an early case, showing small hypopigmented macules on the shoulders. He was quite ignorant of the nature of his disease. When shown the macules, he said that they were merely "skin marks," and that the natives often show such marks. He, of course, mistook them for the small areas of congenital absence of pigment, which are not 
uncommon. The two females were advanced cases, and obvious, and have since been admitted to Ngomahuru. The male is also on his way here for treatment.

Consideration of the Whole Survey.

Consideration of the Whole Survey.

\begin{tabular}{|c|c|c|c|c|c|c|}
\hline & Males. & Females. & Children. & Totals. & Leprosy. & Syphilis. \\
\hline Part I & 1227 & 1943 & 1685 & 4855 & 6 & 30 \\
Part II & 991 & 2023 & 1829 & 4843 & 3 & 13 \\
\cline { 2 - 7 } Totals ... & 2218 & 3966 & 3514 & 9698 & 9 & 43 \\
\hline
\end{tabular}

It is thus seen that out of a total of 9,698 people examined, 9 cases of leprosy were discovered, giving a case incidence of .92 per thousand. 'This is a very low figure, and no doubt below the actual figure. In the Chibi survey the figure was about 7 per thousand.

After consideration of all the facts and experience, I am definitely of opinion that leprosy is not nearly so prevalent in Gutu as in Chibi. There is no doubt that the natives do not know the signs of leprosy in its early stages. If, therefore, leprosy had been at all prevalent in Gutu, we should have seen many more early cases. The nine cases seen might be classified as Early 5, Late 4.

The four late cases might have been expected to remain away for fear of incarceration, but the five early cases being unaware of the fact that they had leprosy, had no reason to absent themselves.

Mr. Fynn also agrees. In his opinion, leprosy is not at all rife in Gutu, for his messengers who constantly travel about the province, do not come across cases. These messengers, by the way, do a month's duty periodically at Ngomahuru, so that they know something of the appearance of leprosy in all its stages.

A little incident of the survey is of interest in this connection. A messenger of the native department came to Mr. Fynn saying that he knew of the whereabouts of a case of leprosy and he would tell him, if Mr. Fynn would promise not to let anybody know who it was that gave him the information. The information was given, and the patient produced. Here was a case of definite hiding of a case and of fear on the part of a native department messenger to give information. I do not, however, think that such a case is the rule, and I believe that the fear of incarceration will rapidly pass away, and is, indeed, doing so already. Three of the nine cases have come to Ngomahuru quite voluntarily, 
and I believe that every single case will appear within the next week or two. There were unmistakable signs that the dread of what used to be nothing more or less than imprisonment is passing away. The system of allowing patients to have visitors (a separate compound is kept for visitors) of permitting non-infective cases to go to their homes occasionally, and of setting an afternoon a week apart for the clerk to write letters for the patients to their relatives and friends, all these are having their good effects. The patient in hospital is no longer considered as dead, as was undoubtedly the case some years ago.

To consider now the sex of the discovered patients. Of the nine, five were males and four females. The usual incidence is about three times as great in males as in females, so that it is evident that the males were absenting themselves.

The estimated population of Gutu is about 50,000, of whom we saw one-fifth. Females put in an appearance more freely than males. Assuming that, had we seen the whole population, we should have discovered not less than 20 female cases.

Adding three times as many men would give a figure of 80 cases, for the whole population or a case incidence of 1.6 per thousand. The correct figure is probably higher than this, in the region of 2 to 2.5 per thousand. This, of course, is mere surmise, but I think it is not far from the truth, and consider that this is a useful figure.

I trust it may be possible to carry out further surveys in the future, and in the light of experience I would recommend that :-

1. It should take place in August or September, not later, not earlier.

2. At least two days should be spent at each centre, to allow time for some treatment and for late comers.

3. The Native Commissioner be asked to bring his tax register.

4. As many native department messengers as possible be employed, mounted on bicycles. 


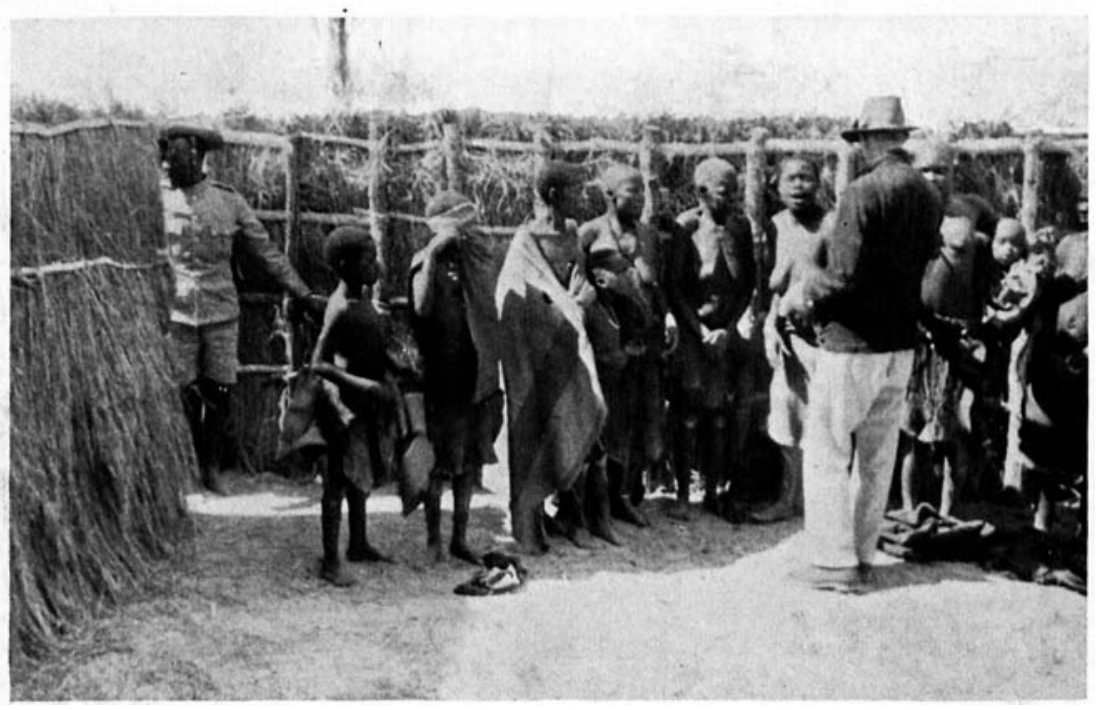

Gutu Leprosy Survey, Southern Rhodesia. Dr. Leggate examining Natives in the Shelter a T Chingomba. 23rd July, 1932.

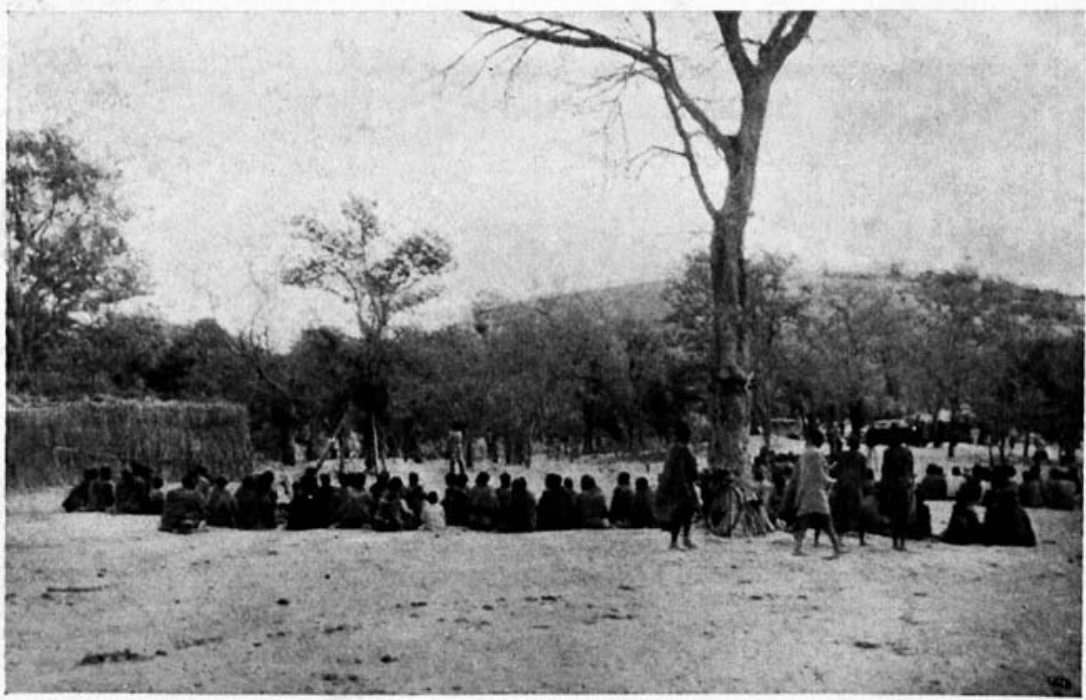

Gutu Leprosy Survey, Southern Rhodesia. awaiting Examination at Baro, 22ND July, 1932. The Station is SHOWN ON LEFT. 


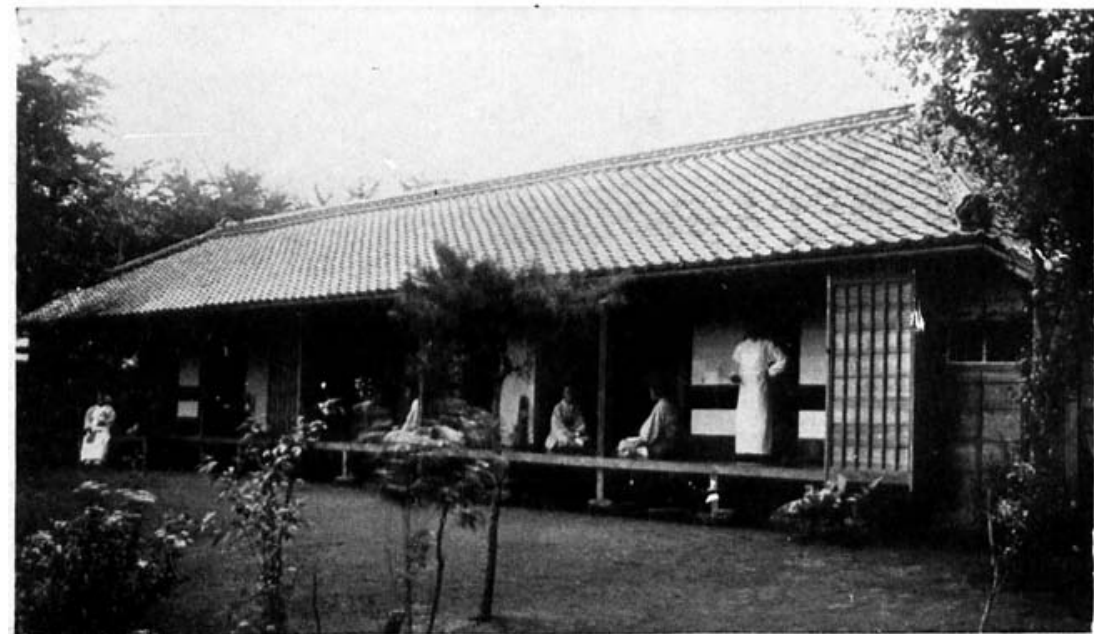

Reproduced by kind permission of the Misson to Lepers.

A Ward for Women in the "I-hai-en" Hone, Meguro, 'Гokyo, Unider the auspices of this Mission to I epliks.

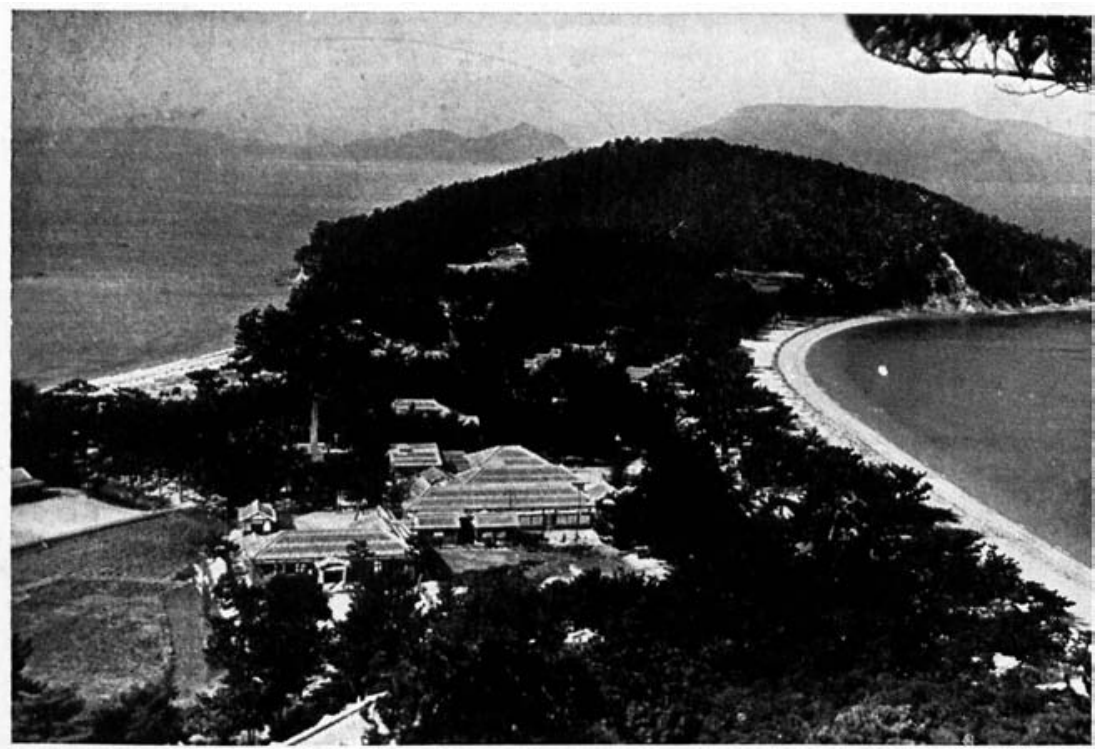

Reproduced by kind permission of the Mission to Lepers.

'The Govfrnment I feprosy Asilum on the Ist.and of Shikoku, near (OSHIMA, Japan. 